\title{
Constructionism and the space of reasons
}

\author{
Kate Mackrell $^{1} \cdot$ Dave Pratt $^{1}$ (D)
}

Received: 2 August 2016 / Revised: 28 January 2017 / Accepted: 3 February 2017 /

Published online: 18 February 2017

C The Author(s) 2017. This article is published with open access at Springerlink.com

\begin{abstract}
Constructionism, best known as the framework for action underpinning Seymour Papert's work with Logo, has stressed the importance of engaging students in creating their own products. Noss and Hoyles have argued that such activity enables students to participate increasingly in a web of connections to further their activity. Ainley and Pratt have elaborated that learning is best facilitated when the student is engaged in a purposeful activity that leads to appreciation of the power of mathematical ideas. Constructionism gives prominence to how the learner's logical reasoning and emotion-driven reasons for engagement are inseparable. We argue that the dependence of constructionism upon the orienting framework of constructivism fails to provide sufficient theoretical underpinning for these ideas. We therefore propose an alternative orienting framework, in which learning takes place through initiation into the space of reasons, such that a person's thoughts, actions and feelings are increasingly open to critique and justification. We argue that knowing as responsiveness to reasons encompasses not only the powerful ideas of mathematics and disciplinary knowledge of modes of enquiry but also the extralogical, such as in feelings of the aesthetic, control, excitement, elegance and efficiency. We discuss the implication that mathematics educators deeply consider the learner's reasons for purposeful activity and design settings in which these reasons can be made public and open to critique.
\end{abstract}

Keywords Space of reasons · Constructivism - Constructionism · Purpose and utility · Reasons

Dave Pratt david.pratt@ucl.ac.uk

Kate Mackrell

katemackrell@mac.com

1 Institute of Education, University College London, London, UK 


\section{Introduction}

Imagine that we have a set of practises that seem to work in the classroom: teachers and students are enthusiastic, hardworking and they perform well on assessments. Now imagine that these practises were developed out of a behaviourist framework. It would be very difficult for many researchers to evaluate these practises in any neutral manner and, most likely, as less and less attention is paid to behaviourist frameworks, the practises would be forgotten.

Thirty years ago, Seymour Papert introduced such a set of practises, developed out of a constructivist framework. Such a framework does not have the negative connotations of a behaviourist framework, but is still problematic. It is possible that as this is increasingly superseded by, for example, enactivism, or activity theory, Papert's practises will be likewise forgotten.

The aim of this article is to show that these practices do not need to be embedded in a constructivist framework and to introduce an alternative framework, based on ideas from contemporary philosophy, that will not only support and validate the practices currently supported by constructivism but also enable the support and development of aspects of the practices not currently supported by constructivism. Our hope is hence that Papert's ideas will continue to inform current practice and give rise to new developments for future practice.

In this paper, we first introduce Papert's constructionism and the way in which it is both connected to and different from constructivism. We then give a brief historical perspective that identifies some of the major issues with constructivism as a theory. Next, we introduce an alternative framework connected to inferentialism and discuss a number of possible objections to using this framework. We then look at the developments in constructionism that have occurred more recently and show how these can be connected with the framework we are proposing. We next re-interpret some aspects of Papert's original descriptions of classroom experience to show the way in which our framework can support these descriptions. In our conclusion, we stress the importance of a framework within which Papert's ideas may be elaborated and further developed and point to a number of future directions for development.

\section{The emergence of constructionism}

In the 1960's, Papert worked with Piaget, whose ideas on intellectual development, framed by Piaget as genetic epistemology, provided a foundation for Papert's desire to create settings in which children would be inspired to think mathematically. In Mindstorms: Children, Computers, and Powerful Ideas (1982), Papert's vision was of children learning mathematics through deep and personal engagement with powerful mathematical ideas embodied in microworlds, environments in which the child could explore and play with mathematical ideas in their creation of personal self-driven projects. $\mathrm{He}$ and his team at MIT invented a new programming language called Logo to promote these ideas and to research the nature of problem solving. The designers of Logo cleverly exploited young children's natural interest in drawing and animation by offering them programming control over the turtle, an on-screen object that would move and draw according to instructions such as FORWARD 50 and LEFT 90. The child was encouraged 
to build programming projects by defining new procedures on the basis of primitive commands or previous definitions. For example, here is a procedure to draw a square:

to square: sidelength

repeat 4 [FORWARD: sidelength RIGHT 90]

end

The meaningful use of mathematical ideas such as distance, angle and variable are thus promoted and developed. After a period in which Logo appeared to have become unfashionable, there is now a renewed interest: Scratch (https://scratch.mit.edu/), a direct descendant of Logo, now claims 4 million users worldwide across a wide range of ages centred around 13 years, and the national curriculum in the UK is promoting coding in schools in place of computer literacy. Nevertheless, it is fair to say that the central tenet in Papert's vision that children could take ownership and control of their own learning stood - and still does stand - in direct opposition to the prevailing approach to schoolbased teaching and learning of mathematics. As the initial concern with problem solving developed, the ideas around Logo and microworlds were formalised into constructionism, which shares with Piagetian constructivism the idea that knowledge is constructed by the individual learner, but adds the idea that learning is most effective when experienced as constructing a meaningful product and stresses the importance of affect.

\section{Constructivism and constructionism}

\section{Types of theory}

diSessa and Cobb (2004) set out a taxonomy of theories that clarify the way in which different types of theory are connected to the practicalities of teaching and learning. They described constructionism as a framework for action: a set of prescriptions for pedagogical strategies, often effective heuristics providing focus and direction to the design of a learning environment, but which fail to separate scientific claims from suggested actions.

These strategies derive from and are justified by more general grand theories and orienting frameworks, which for the purposes of this paper we will refer to as orienting theories. It is clear from Papert's (1982) own accounts that Piaget's work, the basis for constructivism, provides the orienting theory for Papert's vision of constructionism.

We claim that the foundation of constructionism on constructivism is problematic and seek to provide a different foundation in ideas drawn from some aspects of contemporary post-analytic philosophy of mind, which will both deal with an intrinsically problematic aspect of constructivism and include affect. The inferentialism of Robert Brandom is an important part of this foundation, but we also include ideas from John McDowell and David Bakhurst who, while agreeing with many of Brandom's ideas and much of his perspective, would not describe themselves as inferentialists.

\section{Connections and discontinuities between constructivism and constructionism}

Our first step is to elucidate the problematic nature of the relationship between constructivism and constructionism. Papert adopted Piaget's idea that knowledge is 
constructed by the learner but saw his own perspective as more interventionist, involving education as well as understanding. He saw himself as elaborating Piaget's work in order to facilitate the development of different intellectual structures having both logical and emotional form through the design of resonant learning environments. A major aspect was his consideration of the affective component, later elaborated as one aspect of the extralogical, which also included the aesthetic and the intuitive. ${ }^{1}$

Papert also used the 'child as builder' metaphor to consider the materials needed to build and saw the surrounding culture, and in particular accessible computers, as a major source of these materials. He accepted Piaget's distinction between concrete and formal thinking but felt that objects such as computers could shift the boundary separating the two, enabling knowledge that had previously only been accessible through formal processes to be approached concretely.

We note how, over the years, some issues have been progressively elaborated to place an increasing emphasis on the extralogical. In Mindstorms, Logo is described as arising from an interest in enabling the construction of particular mathematical structures, while in Constructionism (Harel and Papert 1991), the roots of Logo are seen more in the search for ways of learning that would deeply engage students. This connects with the Mindstorms idea of the importance of the extralogical in learning, but Papert has moved on from expressing this as in opposition to the logical: it now involves appropriating mathematics in a deeply personal way.

\section{Issues with constructivism}

Constructivism hence does not provide a grounding for many of Papert's ideas. In this section, we will explore some of the ways in which constructivism is problematic in itself. These problems have historical roots; in 1639, Descartes proposed that the mind, the 'I' who thinks, wills, understands and perceives, and the body, a machine that produces representations of perceptible objects for the mind, are distinct.

Descartes also proposed that it is by thinking/reasoning that we reach the truth, whereas beliefs based on the senses may be mistaken. Locke and then Hume countered Descartes' emphasis on reasoning with the insistence that knowledge came from experience and that empirical investigation was necessary. Kant, in synthesising the role of reason and empirical investigation in developing knowledge, held that the world of appearances was constructed by the human mind from sensory matter via a priori cognitive forms in cognition. He described this view as a 'Copernican revolution': instead of cognition conforming to objects, objects, as we experience them, must conform to cognition (Rohlf 2014). He stressed that we cannot know things-inthemselves but only their constructed appearances, which take the form of mental (or inner) representations.

This idea has created huge problems for understanding learning, as it has led to the tacit assumption that all knowledge must involve representation and hence that to learn

\footnotetext{
${ }^{1}$ Note that Papert (1982) saw Piaget as neglecting the affective relative to the cognitive "more from a modest sense that little is known about it than from an arrogant sense of its irrelevance" (p. vii), and Piaget makes clear in his book Intelligence and Affectivity $(1954,1981)$ that the two are intertwined in a child's behaviour, making him rather less of a cognitivist than is commonly believed. However, the constructivism that developed from Piaget's work has not incorporated Piaget's concern with the affective in any significant way.
} 
is to construct such representations. This assumption has distorted the interpretation of a number of theorists - including Piaget, considered by von Glasersfeld (1990) as 'the great pioneer of the constructivist theory of knowing'. For example, McLeod (2015) quotes Piaget (1954) as defining a schema as follows:

a cohesive, repeatable action sequence possessing component actions that are tightly interconnected and governed by a core meaning.

Such a definition does not involve the idea of representation - but McLeod describes a schema as enabling the formation of a mental representation of the world. ${ }^{2}$

Cobb et al. (1992) stress that constructivism in itself does not involve representationalism and that it can be used to bridge the issue with the mind/world divide. However, although they themselves are careful to talk about 'ways of knowing', they point out that many constructivists have uncritically used the idea of knowledge as a representation:

Learning is then characterised as a process in which students gradually construct mental representations that accurately mirror the mathematical features of external representations. (Cobb et al. 1992, p.3)

Another early example is Bruner (1966, cited in Presno 1997), who proposed a theory of child development based on modes of representation:

There are three ways in which individuals represent the real world around them. Through action, icons, and symbols, people convert reality into their own unique portrayal of reality... it is the teacher's job to help the learner find the most economical and powerful ways to represent their world.... (p. 112)

The idea also persists today. Ernest, well-known for his philosophy of mathematics education says the following in a criticism of radical constructivism:

[The cognising subject's] representations of the world and of other human beings are personal and idiosyncratic. Indeed, the construal of other persons is driven by whatever representations best fit the cognizing subject's needs and purposes. (Ernest 2010, p. 41)

Ernest criticises the idiosyncrasy and primarily cognitive character of such representations - but does not criticise the use of 'representation' to describe knowing.

Taylor (2013) identifies this problem as a 'big mistake operating in our culture... that we mis(understand) knowledge as "mediational" (p.61) and points out that the fundamental mistake is to posit an inner/outer structure, with reality outside, our grasp of it inside, and knowledge of and access to the world coming only through some features in the mind or organism. Although the particular idea of representations as mediators has been challenged, mediators may also be thought of as depictions, ideas, beliefs - or the categorical forms used in conceptually structuring the input. Descartes'

\footnotetext{
${ }^{2}$ In contrast, Wilson (2002) identifies Piaget's emphasis on the emergence of cognitive abilities out of a groundwork of sensorimotor abilities as one of the early sources of embodied cognition.
} 
mind-body dualism has been replaced with a mental/physical distinction which most of us take for granted.

Another consequence of Descartes' mind-body split is the neglect of affect in constructing knowledge. Derry (2013) traces the way in which reason and rationality have been separated from emotion as a consequence of this split. Objectivity in scientific enquiry has prioritised the neutral, objective observer, unaffected by personal responses. The possibility and desirability of such an observer has been questioned for some time; affect is certainly on the agenda in mathematics education research and is a key to learning for Papert. However, as noted by Roth (2011), there is no way of incorporating emotion into constructivism as it stands: it remains an awkward add-on.

There are other issues with constructivism. Derry (2013) criticises the characterisation of the world that accompanies an emphasis on constructivism: it is a world devoid of meaning without the contextually sustained activities of participants. In contrast, Papert emphasises the importance of personal meaning. This also allays Roth's (2011) criticism that motivation is not intrinsic to constructivism.

Roth (2011) makes a number of criticisms of the intellectualist position he sees as underlying all current theories of learning, 'from Kant to Piaget and the modern day (radical, social) constructivists' (p.4) which he characterises as concerned with constructions and externalities rather than aspects of life such as emotions. He stresses instead the essential role of the living body in knowing and criticises constructivism for a lack of awareness of people as living beings, with bodies. Papert (1982), in contrast, describes the importance of 'body knowledge': 'You can be the gear, you can understand how it turns by projecting yourself into its place and turning with it' (p. viii).

Another of Roth's criticisms is that the constructivist metaphor cannot explain the intentional learning of anything unknown:

Learning really means appropriating the unintended, something other, something that lies outside of the horizon of the known, something that is foreign/strange. (Roth 2011, p. 8)

Roth claims that 'dabbling' and 'messing about' are much more appropriate metaphors. This has a distinct resemblance to Papert's ideas about bricolage, where something emerges out of what is happening at the time rather than out of any particular intention or plan. An example is the following description of a student who invented a way to hide an object by placing another object on top of it:

She has learned her way around a set of mathematical ideas through manipulating angles, shapes, rates, and coordinates in her program. As a bricoleur, her path into this technical knowledge is not through structural design, but through the pleasures of letting effects emerge. (Turkle and Papert 1991 p. 172)

A further criticism is that the metaphor of construction in constructivism implies constantly being active (in deliberate contrast to 'instructionism' in which the learner is passive) while learning needs the capacity to be affected:

In deciding to take a whiff, we expose ourselves to the new and unknown. We actively expose ourselves and we are also exposed to the unknown (passive): we 
are therefore vulnerable. The first whiff affects us prior to any construction or comparison. Vulnerability precedes knowing. Without vulnerability there would be no knowledge at all. It is only after having been affected that we can begin to think, classify, and relate the experience to something else. (Roth 2011, p. 18)

Papert's 'construction' is certainly active. However, the focus on the purposeful construction of a public object implies that learning needs to involve both being active when performing any action-and being passive in Roth's sense when receiving a feedback on the effect of the action. In addition, Ackermann identifies a sense of loss, and of being open to experience that resonates with Roth's account of vulnerability:

On the other hand, Papert's view that diving into unknown situations, at the cost of experiencing a momentary sense of loss, is also a crucial part of learning. Only when a learner has actually traveled through a world, by adopting different perspectives, or putting on different 'glasses', can a dialogue begin between local and initially incompatible experiences. (Ackermann 2001, p. 10)

Constructivism hence faces some significant criticisms that do not apply to constructionism as well as not providing an adequate grounding for constructionism.

\section{An alternative to constructivism}

There are a number of ways currently in which the mind-body or mind-world split is being addressed in mathematics education, including enactivism, derived from biology (see Reid (2014) for a comprehensive account of enactivism in mathematics education research) and embodied mathematics (following Lakoff and Nunez (2000), derived from linguistics and cognitive psychology). We will introduce an alternative in this paper. As the problem originally arose in philosophy, it is worth considering whether any of the contemporary ways in which the problem is being addressed in philosophy are of relevance in mathematics education, and whether they might also address the issue of providing a theoretical basis for constructionism.

The first issue is to show that there is no need for 'internal' representations in order to experience the world. McDowell (1996) uses arguments from Kant and more recent philosophers in the analytic tradition such as Sellars and Davidson to in effect erase the divide between mind and world. Writing about the importance of McDowell's work for education, Bakhurst (2011) gives this summary:

In perception, what we take in is not raw data that the mind has to work up and conceptualise before it can form the basis of judgement. The content of our experience is that things are thus and so. The deliverances of perception are already conceptual in character and hence fit to yield judgement and to serve as ground for belief. If we construe experience in this way, we can think of it not as a mediator that comes between us and things as they are but as openness to reality. Experience discloses the world to us. (Bakhurst 2011, p. 7) 
There is hence no need for the mind to construct its awareness of the world. This is similar to the way in which Taylor (2013), working within the continental tradition in philosophy and drawing on Heidegger, Merleau-Ponty and Wittgenstein, replaces mediational theories of knowledge with contact theories: 'the contact of living, active beings, whose life form involves acting in and on a world which also acts on them. These beings are at grips with a world and each other ... (Taylor 2013, p.73)'.

The second issue is to identify what learning consists of if it is not about constructing knowledge. We first introduce the term, 'the space of reasons':

'in characterizing an episode or a state as that of knowing, we are not giving an empirical description of that episode or state; we are placing it in the logical space of reasons, of justifying and being able to justify what one says' (Sellars 1963, p.

In one sense, this is simply restating the traditional philosophical definition of knowledge as justified true belief, but the image has a much wider scope. McDowell (2005) would include in the space of reasons any phenomena, such as behaviour, beliefs and desires which can be made intelligible as manifestations of a responsiveness to reasons. Behaviour becomes intelligible (or, loosely, makes sense) when seen as intentional action. Reasons can be contrasted with causes: the reason the fridge door just opened is that I was thirsty and knew there was some juice in the fridge. The cause of the fridge door opening is the particular movements I made with my hand on the handle. A key to interpreting phenomena as belonging within the space of reasons is whether the person holding the belief or desire or engaging in the action is aware that the belief, desire or action could be different and can ask the question whether their belief, desire or action should be as it is. The thirsty baby responding to breast or bottle is not acting in the space of reasons.

Brandom $(1995,2000)$ sees standing in the space of reasons as an abstraction from the concrete practises of giving and asking for reasons and as dependent on social articulation. He gives the example of a thermometer's and a human's response to the temperature dropping below 70 degrees to illustrate what it means to stand in the space of reasons: the human can assert that 'it's 70 degrees outside' knowing both what would be evidence (or reasons) for such a claim and what would follow from the claim (what the claim would be reasons for). Another example he gives is the difference between the 2-year-old and the 7-year-old who state that the house is on fire: the 7-yearold is making a claim, is standing in the space of reasons, as she knows that evidence for her claim is that the kitchen is full of smoke and flame and that it follows that the family is in danger and must flee. Brandom rejects the priority given to representations and argues that knowing is constituted in the game of giving and asking for reasons. Representations are invented as a result of that game. The square in the Logo example above is generated through just such an interactive process, with the child offering reasons for a square in the form of instructions, drawing on feedback from the computer and then further inferring how the square might be generated. Human utterances and actions are embedded with intent, which others attempt to interpret, and humans seek meaning in the discourse of others. By giving and asking for reasons, humans keep score of the 'correctness' of their meanings in order to seek out normativity.

Bakhurst (2011) has begun to develop a genetic account of knowing based on the ideas of McDowell and Brandom. He claims that human minds develop through 
initiation into the space of reasons such that our thoughts and actions are increasingly guided by what there is a reason to think about or do. The thirsty baby can only cry: the thirsty adult acts on the belief that there is a juice in the refrigerator and undertakes a set of actions which will ultimately result in drinking the juice - or alternatively gives the juice to the baby and then gets water for herself. There is a striking similarity with Papert here: 'being intelligent means being grounded, connected, and sensitive to variations in the environment' (Ackermann 2010, p.4).

The alternative to constructivism that we propose is to consider the learning of mathematics as just such an initiation into the space of reasons, with focus on thoughts, feelings and actions that can be considered to be connected to mathematics. This would clearly incorporate both the logical structure of mathematical argument within mathematics itself (in contrast to enactivism, which cannot address the nature and growth of mathematics itself (Reid 2014)) and also, for individual learners, the reasons why mathematics is considered important and the personal reasons for engaging (or otherwise) in mathematics. The focus on reason will also necessitate overt consideration of an ethical dimension in mathematics education. As the space of reasons is a key concept to all three philosophers, we will tentatively use 'participation in the space of reasons' as a label for this framework. As noted above, this includes significant ideas from inferentialism but also ideas from philosophers who would not identify as inferentialists. We will also refer to the 'mathematical space of reasons' as any aspect of the space of reasons that is of particular importance in the learning of mathematics, with the proviso that there is no firm boundary between this and the 'space of reasons' as a whole.

An issue, however, is that it is very hard to use the word 'reason' without falling back into a number of dichotomies. The first dichotomy is that of intellect and emotion. One of the definitions of 'reason' (from the Oxford Dictionary) is 'the power of the mind to think, understand, and form judgments logically', which gives no link with emotion. Indeed, 'cold reason' is synonymous with 'lacking in passion, emotion enthusiasm, ardour, etc.' (Dictionary.com). However, if we use a reason as 'a cause, explanation, or justification for an action or event' (also from the Oxford Dictionary), this difficulty does not arise: reason encompasses both creating a rigorous proof of Pythagoras' theorem, the decision to not engage with attempting to understand such a proof because of anxiety and a lack of confidence, and persevering with programming a turtle because beautiful patterns emerge. This is consistent with McDowell (2005).

McDowell's emphasis on persons as 'inhabitants of the space of reasons' has been criticised as painting an unduly intellectualistic or rationalistic portrait. Bakhurst (2011) discusses this misconception, portraying reasons in the contexts of moral sensibility, passivity and creativity and also mood and responsiveness to music.

The second dichotomy is the precise mind/world split that we are attempting to avoid. It is very easy to picture ourselves as having internal reasons (in our minds) that cause our external actions (in the world), or to consider the space of reasons as an inner, mental space. McDowell (1995) is adamant that this is not the case, and McDowell (2013) emphatically rejects the 'Myth of Mind as Detached': 'Self-awareness in action is practical, not theoretical. It is a matter of an "I do" rather than an "I think"'(p. 45). Recent research in cognitive psychology is also helpful here, assuming that experience of mind arises from experience of conscious thought. In a review of the limitations of conscious thought, Masicampo and Baumeister (2013) cite an evidence that conscious 
thought is too slow to initiate behaviour: unconscious processes are much earlier indicators of action, even for complex decisions, and also that unconscious processes are capable of initiating and guiding action. Masicampo and Baumeister also describe research in which participants provide plausible but false reasons for their actions or explain decisions that they did not in fact make. This is in stark contrast to Descartes' assumption that the mind is in control of the body or Kant's assumption that our cognitive structure is transparent to us. The implication is that reason, as the explanation of action, cannot be equated with conscious thought, or the mind.

A tension arises, however. Both McDowell and Brandom argue for the importance of the articulation of reasons. Although McDowell does not equate articulation and reason, he considers the development of language as the entry-point into the space of reasons, and Brandom would consider that his 7-year-old who says the house is on fire is only entitled to her commitment to this claim if she is able to verbally justify it. Bakhurst differs in emphasis, however. In a vivid analysis of Mr. Gradgrind's classroom (from Dickens' Hard Times), he contrasts the boy who is considered to know what a horse is, because he can list its properties with the girl who could not list these properties but who lived with horses and whose interaction with them showed a responsiveness to reasons, even if she could not articulate these. There is, however, an important aspect of the space of reasons involved in verbal articulation; Bakhurst sees our central task as opening up our views to critique:

'we emerge as rational beings already possessed of views about the good, however partial, confused or incoherent they may be. Our task is to bring those views to consciousness and subject them to critical thought.' (Bakhurst 2011, p.

There is currently much debate within philosophy about the limits of reason and rationality. For example, Dreyfus (2013) argues that behaviour such as standing at a particular distance in conversation is charged with meaning-but that individuals are not normally able to cite such meanings as reasons for their behaviour and may not even be aware of the behaviour, and are hence not acting on the basis of rational mindedness. McDowell (2013) acknowledges that such behaviour does not involve rational agency but makes a distinction between this behaviour and that of a chess master engaged in lightning chess. The act of giving a rational explanation may disrupt the flow of the chess master and hence will not take place during the game, but the player is indeed acting rationally. Such rationality need not involve deliberation about what to do before acting.

Another dichotomy that may arise is that between the abstract and the concrete. Reason can be seen as abstract rationality-irrelevant, remote and difficult for many learners. Derry (2013) illustrates the way in which this criticism has been made of Vygotsky (as, although focusing on the concrete details of the child's experience and engagement with the world, he also valued science, rationality and progress) and defends him by showing that he had a very different conception of abstraction and rationality from that of his opponents; Vygotsky's ideas were informed by Spinoza and Hegel rather than Descartes and Locke. For example, in looking at the opposition between every day and scientific concepts, Vygotsky follows Hegel in seeing a clash of opposites as resulting in a transcendence to which both contribute. The old, everyday 
meaning is retained in the new: a scientific concept is weak if it is not saturated with an immediate concrete experience. Derry specifically links Vygotsky's thought to Bakhurst, Brandom and McDowell.

As implied above, some of McDowell's most important ideas are also part of the continental tradition in philosophy, and the natural question is 'Why bother with the space of reasons? Why not pursue phenomenological ideas such as being-in-theworld?' One of the reasons for focussing on the philosophers that we have chosen is precisely the link that has already been made with Vygotsky. Vygotsky (1930) saw representations such as 'language, different forms of numeration and counting... algebraic symbolism, works of art, writing, schemes, diagrams, maps, blueprints...' as psychological tools. This complements Brandom's idea that representations arise in the game of giving and asking for reasons. Derry's work shows that, via Vygotsky, many of the ideas that we are seeking to elaborate are already important in contemporary educational research. Bakhurst (2011) also sees important similarities between Vygotsky and McDowell and advocates the importance of Vygotsky's ideas in facilitating the entry into and development within the space of reasons that he sees as the goal of education. Another reason is that mathematics itself has a highly inferential nature, making Brandom's ideas of particular relevance. This does not, however, preclude the further exploration of ideas from phenomenology in the future.

\section{Further developments in constructionism}

We have suggested that a consideration of learning as initiation into the space of reasons will alleviate the problem with learning seen as constructing representations and distinct from affect. We turn now to more recent developments in constructionism which have also dealt with these issues and show how these initiatives, while underscoring the distinction between constructivism and constructionism, align with the idea of participation in the space of reasons.

A major issue in constructivism is the potential lack of correspondence between knowledge constructed by the learner and acceptable mathematical knowledge, welldocumented in the literature on misconceptions. However, the problem is even worse: not only may learners fail to construct acceptable mathematical knowledge but they may also construct different knowledge in different settings. In contrast to Piaget, who saw intellectual development as involving the progressive de-contextualization of knowledge (Ackermann 2010), Papert stressed the importance of the context in which individuals learn - but contexts both enable and constrain learning. The work on situated cognition, beginning with Lave (1988), has shown that knowledge learned in one setting is unlikely to be applied in another. In developing an account of how mathematical abstraction might take place within a constructionist (and also constructivist) framework, Noss and Hoyles (1996) challenged the traditional view of mathematisation as moving the mathematics from action to cognition. Although they do not describe it as such, this view may be seen as a product of the mind/world split, in which actions-in-the-world need to be internalised as cognitions-in-the-mind. In contrast, Noss and Hoyles implicitly stress the connection between mind and world: 'we want to put forward a case for learning as the construction of a web of connections between classes of problems, mathematical objects and relationships, 'real' entities and 
personal situation-specific experiences' (Noss and Hoyles 1996, p. 105). A key construct is that of situated abstraction, both process and product, which describes the way in which learners construct mathematical ideas by drawing on this web in particular settings. They stress that abstracting 'can be seen as a way of layering meanings, connecting between ways of knowing and seeing rather than replacing one kind of meaning with another' (Noss and Hoyles 1996, p. 122).

We note that both situated abstractions and reasons arise from context, the immediate world in which the learner is situated. To explore further the connections between the two, we introduce Brandom's idea of the inferential nature of the space of reasons. For Brandom, two propositions such as 'there is smoke and flame in the kitchen' and 'we must leave the house' are connected if one can be inferred from the other, possibly via the intermediary of other propositions such as 'the house is on fire' and 'we do not have a fire-extinguisher'. Developing within the space of reasons involves an increasing awareness of the inferential connections in the world. We can take this beyond propositions: we hug a friend who is feeling low in the belief that this will comfort her. Situated abstraction is likewise about connecting: learning is about increasingly knowing connections. However, the nature of such connections is left unexamined, which is problematic; it is tempting to see a situated abstraction as an inferential proposition drawn on the basis of what is known about a context and what this would entail in action, but this is not yet warranted. Brandom gives us a way to begin to discuss which connections may be important, which are incidental and which, of the huge number possible in any moment of lived experience, may not be made at all. We hence think that there may be fruitful comparisons made between the space of reasons and the web of connections - once 'connection' has been elaborated.

Another development in constructionism focuses on its extralogical aspect. Ainley et al. (2006) proposed the terms 'purpose' and 'utility'. Purpose refers to the perspective of the pupil. A purposeful task is defined as one that has a meaningful outcome or solution. Purpose may be quite distinct from the teacher's objectives for mathematical learning. Utility refers to the sense of power for a mathematical idea that a child might appreciate when they see how mathematical concepts or methods enable them to make progress in their task. The following situation illustrates these constructs:

A task which we have used on a number of occasions is that of designing a paper spinner... In this task the purpose for the pupils is clear: to make a spinner that will stay in the air for as long as possible. In investigating aspects of the design, for example, by changing the length of the wings, pupils record results of test flights on a spreadsheet (the wing length and time of flight). Their activity offers opportunities to use a number of mathematical ideas, including measurement of length and time, decimal notation, graphing and the use of measures of average. (p. 16)

The constructs of purpose and utility bring motivation and engagement to a central place in constructionism. In contrast, motivation, as noted above by Roth (2011), is not intrinsic to constructivism. There is a striking resemblance between the situation involving the spinner described above and the situation Roth describes (taken from research in Kharkov in the 1930s) to illustrate the importance of the object/motive in learning:

...the psychologists changed the structure of the activity, now formulating the object/motive to build planes that covered a certain distance. After building their 
first versions, many students found that their model planes crashed prior to making it to the finish line. As they intended to get their planes across the line, they began to seek ways of making them go farther; and, lo and behold, they became interested in the physics of flying. They began to ask instructors and read available materials. (p. 16)

The importance of these ideas in the mathematical space of reasons is clear: 'purpose' is the child's reason to engage in an activity, while 'utility' might involve both the reason that learning the mathematical idea is seen as desirable and the child's growing responsiveness to the reasons embedded in the mathematical idea through its relationship to her own reasons for engaging in the activity.

\section{A brief re-interpretation of constructionism in action}

We have argued that contemporary philosophies in which the concept of the space of reasons plays an important role provide a better theoretical basis for constructionism than for constructivism. We can gain a better foothold on this proposition by reinterpreting some reported learning episodes using the mathematical space of reasons.

Pratt and Noss (2002) described a situation in which students were engaged in trying to mend a computer-simulated 'broken' die. The students (10-11 years of age) simulated the tossing of the die and made the observation 'the more times we throw the die, the more uniform is the pie chart' (the pie chart displayed the number of occurrences of each side of the die). This statement is both a situated abstraction and, in Brandom's terminology, a commitment to an inference about the die's behaviour. The question of the students' entitlement to this commitment arises: can the students explain why this is the case and what might follow from this? Brandom considers that interaction takes the form of giving and asking for reasons during which entitlement to commitments may be queried. In this case, the on-screen behaviour of the die enabled the students to query their own entitlement to this commitment.

These reasons however include purpose and utility as might be better understood by a representation of an episode from Mindstorms in which a child was shown how to control a cybernetic turtle, using commands such as FORWARD 100 and RIGHT 90. Being able to make the turtle move and then draw was sufficiently engaging to carry most children through the initial learning process. In our terminology, the child was being offered a reason to engage with the turtle, a purpose that the child readily adopted. In the terminology of Ainley et al. (2006), this purpose may not in itself reflect the learning objectives of the teacher or indeed those of the designers of Logo. Papert described how the child needed to extensively explore these and other related commands to gain mastery, a process that involved the child in a sustained enquiry as to the reasons for the turtle's behaviour. The child had a clear purpose to activate the turtle, and to do this, the child needed to be able to explain how it operated.

The initial activity typically developed, according to Papert, into early programming, when the child was introduced to the metaphor of teaching the turtle a new word. Papert mentioned how the child might program new words such as SQUARE or TRIANGLE but crucially appended the phrase 'or whatever the child wishes'. The sense of control over the turtle was supplemented for the child by a sense of control 
over her own learning. For example, the child, who decided to teach the computer HOUSE, exploiting SQUARE for the walls and TRIANGLE for the roof, initiated her own interaction with the turtle involving asking for reasons that explain the turtle's behaviour and observing the feedback as the turtle giving reasons. The child began to appreciate the utility of programming to create movement.

Learning mathematics involves becoming inculcated into the practice of mathematics. From the perspective of participation in the mathematical space of reasons, mathematical knowledge includes the modes of enquiry that are prioritised by the discipline and articulate the nature of the subject. Papert's approach places emphasis on these reasons. In the above example, the child's inquiry process involved experimentation, testing, accounting for behaviour and debugging, all targeted at inferring commitments, making them open to critique, and testing entitlement to hold these commitments.

In another episode from Mindstorms, Papert described the creation of a spiral by starting with the SQUARE program but making the side of the square a little longer at each step so that the shape spiralled outwards, and ultimately writing a short and elegant program using variable and simple recursion. The child recognised the beauty that mathematicians recognise in the recursive program when, with a little help, she created such a program for herself. The spiral program also offers an example of how variable can be a powerful means of communicating instructions to a computer. Mathematics teachers typically struggle with the teaching and learning of algebra, because they lack resources to enable the child to give and ask reasons for variable. The desperate question so often asked by the child in the conventional math classroom after several lessons of early algebra, 'But what is this ' $x$ "?', betrays the lack of utility that the child is feeling for variable. In contrast, making use of variable in order to create a spiral imbues algebra with utility. The mathematical knowledge about variable is made meaningful, because it has become part of the space of reasons during the child's activity to create a spiral on screen. This episode shows how reasons can involve beauty, elegance and utility.

These episodes are intended to illustrate the diversity of reasons, given and asked for, fusing powerful ideas in mathematics, mathematical methods of enquiry, logic, utility, generalisation and abstraction, with purpose, aesthetic appeal, elegance and excitement.

\section{Conclusion}

In the preface to Mindstorms, Papert conveyed his own deep love of gears and how the turtle was an attempt to offer a general-purpose tool for mathematical thinking that performed a similar role to that undertaken by gears for him as a young boy. However, Papert was unable to elaborate his sense of the affective aspect within the theoretical compass of constructivism. The link between constructivism and constructionism became increasingly tenuous, with the introduction of purpose and utility, webbing and situated abstraction. Although not intended by Piaget, and not acceptable to constructivists such as Cobb, constructivism has also allowed a tacit, but questionable, identification between knowledge and representation.

In this paper, we have followed some contemporary developments in the philosophy of mind and conceptualised learning as initiation into the space of reasons, which incorporates all types of reasons: personal engagement, dialogue and critique, the embedding of reasons in artefacts and in the logical structure of mathematics itself. 
By stressing the importance of the inferential rather than the representational, we can move away from the metaphor of 'constructing knowledge' to seeing mathematical knowing as participating in a space of interconnecting reasons. These ideas connect well both with Papert's aims and with later developments in constructionism. We hence propose to replace constructivism with participation in the space of reasons as an orienting theory for constructionism.

Beyond giving constructionism a more adequate theoretical base, there are a number of reasons why connecting constructionism to participation in the space of reasons is important. The first of these is to enable elaborations within constructionism itself. We have indicated the way in which reason is linked with personal engagement and hence gives a means by which affect is seamlessly a part of constructionism.

Another important elaboration is a consideration of the social dimension of learning. The omission of any reference to this dimension up to this point in the paper does not do justice to the space of reasons: Bakhurst and Brandom in particular stress its social nature, and Bakhurst concurs with Vygotsky on the social nature of mind. The omission is rather more to do with the lack of elaboration of the social in constructionism. We looked at papers from the 2016 Constructionism in Action conference proceedings and found that 'social' was used frequently as an unproblematized add-on (e.g. in mentioning but not elaborating upon the social context). Only two papers made any attempt to elaborate this within constructionism: Benton et al. (2016) and Brady et al. (2016), although this is problematized in the latter.

Can a group of learners engage in collective learning activities that are constructionist in nature?...We argue that this is indeed possible...(p. 61)

A third paper (Fields et al. 2016) presents an interesting approach, designed with the goal that 'all kids would go deep into learning key programming concepts while still supporting their personal interests'. They effectively incorporated an approach taken from art studio design involving student project work (the bulk of the time), brief demonstration lectures, design criticism and exhibition. The aspects of design criticism and exhibition would in particular fit within the space of reasons and may point to ways in which constructionism could more integrally incorporate the social through a consideration of ways to engage students in the giving and asking for reasons.

We anticipate a number of possibilities for future research, focussed on the deep consideration of learners' reasons for purposeful activity and design settings in which these reasons can be made public and open to critique. Exploring connections within the space of reasons may give us a new insight on and means to critique the design of tools for learning in constructionist environments, ranging from physical/virtual artefacts such as manipulatives and technology through less tangible artefacts such as representations and tasks. A highly important aspect of such analysis is that reasons will necessarily include all motivators for human action, including the aesthetic, the affective and the ethical. We feel very often that such reasons are not made visible or are not taken sufficiently seriously, in particular when they conflict. This may be particularly the case when an intervention 'fails'.

By placing reasons at the core of knowing, we have the theoretical grounding to enable attention to be paid to the importance of personal relationships, logical structures, beauty, morality and indeed all aspects of what it is to be human and to be practising mathematics. 
Open Access This article is distributed under the terms of the Creative Commons Attribution 4.0 International License (http://creativecommons.org/licenses/by/4.0/), which permits unrestricted use, distribution, and reproduction in any medium, provided you give appropriate credit to the original author(s) and the source, provide a link to the Creative Commons license, and indicate if changes were made.

\section{References}

Ackermann, E. (2001). Piaget's constructivism, Papert's constructionism: what's the difference? Future of learning group publication, 5(3), 438. http://learning.media.mit.edu/content/publications/EA.Piaget\%20_ \%20Papert.pdf, Accessed 19 April, 2015.

Ackermann, E. (2010). Constructivism(s): shared roots, crossed paths, multiple legacies. In Proceedings of Constructionism 2010. http://citeseerx.ist.psu.edu/viewdoc/download?doi=10.1.1.473.6201\&rep=rep1 \&type=pdf. Accessed December 20, 2015.

Ainley, J., Pratt, D., \& Hansen, A. (2006). Connecting engagement and focus in pedagogic task design. British Educational Research Journal., 32(1), 23-38.

Bakhurst, D. (2011). The formation of reason. Oxford: Wiley-Blackwell.

Benton, L., Hoyles, C., Kalas, I., \& Noss, R. (2016). Building mathematical knowledge with programming: insights from the ScratchMaths project. In A. Sipitakiat \& N. Tutiyaphuengprasert (Eds.), Constructionism in action: conference proceedings constructionism 2016 (pp. 25-32). Bangkok: Suksapattana Foundation.

Brady, C., Weintrop, D., Anton, G., \& Wilensky, U. (2016). Constructionist learning at the group level with programmable badges. In A. Sipitakiat \& N. Tutiyaphuengprasert (Eds.), Constructionism in action: conference proceedings constructionism 2016 (pp. 60-67). Bangkok: Suksapattana Foundation.

Brandom, R. (1995). Knowledge and the social articulation of the space of reasons. Philosophy and Phenomenological Research, 15(4), 895-908.

Brandom, R. (2000). Articulating reasons: an introduction to inferentialism. Cambridge, MA: Harvard University Press.

Bruner, J. S. (1966). Toward a theory of instruction. Cambridge: Belkapp Press.

Cobb, P., Yackel, E., \& Wood, T. (1992). A constructivist alternative to the representational view of mind in mathematics education. Journal for Research in Mathematics Education, 23(1), 2-33.

Cold [adjective 4]. In Dictionary.com. http://dictionary.reference.com/browse/cold. Accessed Oct 21, 2015.

Derry, J. (2013). Vygotsky: philosophy and education. Chichester: Wiley-Blackwell.

diSessa, A., \& Cobb, P. (2004). Ontological innovation and the role of theory in design experiments. The Journal of the Learning Sciences, 13(1), 77-103.

Dreyfus, H. (2013). The myth of the pervasiveness of the mental. In J. Schear (Ed.), Mind, reason and beingin-the-world: the McDowell-Dreyfus debate (pp. 15-40). New York: Routledge.

Ernest, P. (2010). Reflections on theories of learning. In B. Sriraman \& L. English (Eds.), Theories of mathematics education (pp. 39-47). Berlin: Springer-Verlag.

Fields, D., Quirke, L., Horton, T., Maughan, J., Velasquez, X., Amely, J., \& Pantic, K. (2016). Working toward equity in a constructionist scratch camp: lessons learned in applying a studio design model. In A. Sipitakiat \& N. Tutiyaphuengprasert (Eds.), Constructionism in action: conference proceedings constructionism 2016 (pp. 290-297). Bangkok: Suksapattana Foundation.

Harel, I., \& Papert, S. (Eds.). (1991). Constructionism. Norwood: Ablex.

Lakoff, G., \& Nunez, R. (2000). Where mathematics comes from: how the embodied mind brings mathematics into being. New York: Basic Books.

Lave, J. (1988). Cognition in practice. Cambridge: Cambridge University Press.

Masicampo, E. \& Baumeister, R. (2013). Conscious thought does not guide moment-to-moment actions-it serves social and cultural functions. Frontiers in Psychology, http://journal. frontiersin.org/article/10.3389/fpsyg.2013.00478/full. Accessed September 22, 2015.

McDowell, J. (1995). Knowledge and the internal. Philosophy and Phenomenological Research, 15(4), 877893.

McDowell, J. (1996). Mind and world. Cambridge: Harvard University Press.

McDowell, J. (2005). Sellars and the Space of Reasons. http://www.scribd.com/doc/137428240/JohnMcDowell-Sellars-and-the-Space-of-Reasons\#scribd. Accessed September 202015.

McDowell, J. (2013). The myth of the mind as detached. In J. Schear (Ed.), Mind, reason and being-in-theworld: the McDowell-Dreyfus debate (pp. 41-59). New York: Routledge. 
McLeod, S. (2015). Jean Piaget. http://www.simplypsychology.org/piaget.html. Accessed January 19, 2017.

Noss, R., \& Hoyles, C. (1996). Windows on mathematical meanings: learning cultures and computers. London: Kluwer Academic Publishers.

Papert, S. (1982). Mindstorms: children, computers and powerful ideas. London: Harvester Press.

Piaget, J. (1954). Intelligence and affectivity: their relationship during child development. Palo Alto: Annual Review, Inc..

Pratt, D., \& Noss, R. (2002). The micro-evolution of mathematical knowledge: the case of randomness. Journal of the Learning Sciences, 11(4), 453-488.

Presno, C. (1997). Bruner's three forms of representation revisited: action, pictures and words for effective computer instruction. Journal of Instructional Psychology, 24(2), 112-118.

Reid, D. (2014). The coherence of enactivism and mathematics education research: a case study. Avant, 5(2), $137-172$.

Rohlf, M. (2014), Immanuel Kant, In E. Zalta (Ed.) The Stanford Encyclopedia of Philosophy. http://plato. stanford.edu/archives/sum2014/entries/kant/. Accessed September 22, 2015.

Roth, W.-M. (2011). Passibility: at the limits of the constructivist metaphor. Dordrecht: Springer.

Sellars, W. (1963). Empiricism and the philosophy of mind. In W. Sellars (Ed.), Science, perception and reality (pp. 127-196). London: Routledge \& Kegan Paul.

Taylor, C. (2013). Retrieving realism. In J. Schear (Ed.), Mind, reason and being-in-the-world: the McDowellDreyfus debate (pp. 61-90). New York: Routledge.

Turkle, S., \& Papert, S. (1991). Epistemological pluralism and the revaluation of the concrete. In I. Harel \& S. Papert (Eds.), Constructionism (pp. 161-191). Norwood: Ablex.

von Glasersfeld, E. (1990). An exposition of constructivism: why some like it radical. Journal for Research In Mathematics Education - Monograph, 4, 19-29.

Vygotsky (1930). The instrumental method in psychology. https://www.marxists.org/archive/vygotsky/works/1930 /instrumental.htm. Accessed September 15, 2015.

Wilson, M. (2002). Six views of embodied cognition. Psychonomic Bulletin and Review, 9(4), 625-636. 